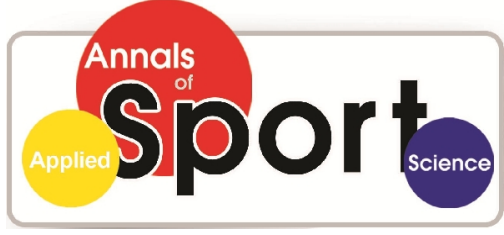

www.aasjournal.com

ISSN (Online): 2322 - 4479

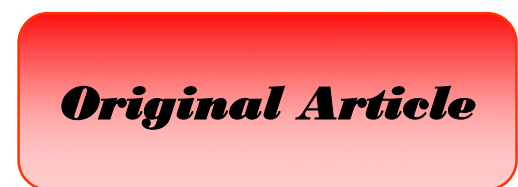

Received: 19/12/2013

Accepted: 20/02/2014

\title{
The Effect of Skill Complexity during Different Time Lags on Bilateral Transfer
}

\section{Zahra Zolfaghari*, Ehsan Zareian, Zahra Salman}

- Department of Motor Behavior, Faculty of physical education and sport sciences, Allameh Tabataba'i University, Tehran, Iran.

\begin{abstract}
The present paper aims to study the effect of skill complexity during different delays on bidirectional transfer on bidirectional transfer of tracking task in different stages (pretest, acquisition phase, immediate transfer, one-day delayed transfer, two-day delayed transfer, and seven-day delayed transfer). Three variables including handedness, time lagges, and skill complexity were studied. This study was a semi-empirical and applied research and a pretestposttest plan with two experimental groups was used. Statistical sample included 28 volunteer girl students, with a mean age of $16 \pm 0.93$ years old, who were all right-handed and had no experience of performing the tracking task. After initial familiarization with designed software, the subjects were randomly divided into two groups of right practice and left practice. The results revealed significant effects of time lags and skill complexity on bidirectional transfer $(\mathrm{p} \leq 0.05)$, as at all stages of research more bidirectional transfer was observed in easy task compared with the hard one. The highest bilateral transfer in easy and hard tasks was found in the second and the seventh day, respectively. Possible reasons for these results include the differences in task processing in terms of skill complexity and the impact of special features of continuous task on retention. Transfer from non-dominant hand to dominant one occurred more frequently than the reverse mode in both groups, which is probably due to higher speed of transfer of data from the right hemisphere to the left hemisphere in the right-handed.
\end{abstract}

Key Words: Immediate Transfer; Delayed Transfer; Easy Tracking Task; Complex Tracking Task.

Corresponding Author:

Zahra Zolfaghari

E-mail: z_zolfaghari@ymail.com 


\section{INTRODUCTION}

Education and educational methods make up a key element in any field of science. A knowledgeable coach is always looking for a way to achieve the highest efficiency in the least possible time (1). One of the common ways to speed up the process individual success is the principle of bilateral transfer, also known as behavior transfer or behavior training. When the transfer of learning facilitates learning in similar tasks but with a symmetric organ, it is called bilateral transfer (2). Many scientists have defined bilateral transfer as a form of motor learning which is transferred from one side of body to the other one (3) or a form of learning that is organized by the mechanism of cerebrum that can be measured by cognitive tasks involving sensory component (4).

Type of task, its complexity rate, and its possible impact on bilateral transfer are of issues discussed in bilateral transfer. Most studies have investigated bilateral transfer in sport skills and in the range of fundamental skills, easy tasks, and movement patterns, in which there was the lowest level of control over confounding variables in terms of grading practices. However, even in the few experimental studies conducted on bilateral transfer, the effect of skill complexity has not been evaluated yet and a more complete conclusion is subjected to further studies (5). A designed easy and hard tracking task was used in the present studying aimed at minimizing the influence of confounding variables and determines the impact of skill complexity on bilateral transfer.

Another noteworthy point in this regard is persistency. Studied in this area have been conducted using the tests which are performed immediately after exercise finishes, so transfer persistency could be measured accurately (6). One of the most important points that need to be explained is that whether transfer from an organ to its symmetric organ is persistent or it merely takes place temporarily. Ghaleh et al. (2009) compared immediate and delayed bilateral transfer in throwing skill in children and adults. Their findings showed no significant difference between immediate and delayed bilateral transfer (7). The same results were obtained in study conducted by Liu and Wrisberg (2005) on immediate and delayed bilateral transfer in throwing skill in girls and boys (5). Time interval between exercise and delayed transfer and inadequate training of skill were mentioned for these results and no impact of time on transfer rate. Hence, more accurate conclusion on delayed bilateral transfer has been handed over to further studies in this area (5).

Transfer direction is another important issue. Answer to the question that whether transfer is done from superior organ to the non-superior one or vice versa has attracted the attention of researchers. Reviewing the previous studied on this issue reveals different and conflicting findings. In Darden (1995), Teixeira (2000), Baliarsing, Doi and Hattori (2002), Noguchi et al. (2009), and Keshavarzi and Farokhi (2006) observed the same result (8-12). In contrast, other studies have indicated that most directions occur from non-superior organ to the superior one. Uehara (1998), Weiglet (2002), Kumar and Mandal (2005), Inui (2005), Stoeckel et al. (2007), Cote, Kimmerle, and Paterson (2007), Pan and van Gemmert et al (2013), Bagherzadeh et al. (2004), and Rafiee, Vaezmousavi, and Abdoli (2010) had the same findings $(6,13-20)$.

Now, according to the fact that determination of the effect of skill complexity on bilateral transfer, persistency, and direction of most transfers can help individuals to save time and energy to learn motor skills and also be effective in rehabilitation of athletes and the injured, apparent contradictions in terms of bilateral transfer, and paucity of studies examining the impact of skill complexity on bilateral 
transfer, the present study is seeking the answer to the following questions:

- How is immediate and delayed bilateral transfer in easy and complex tracking task?

- Do the changes in difficulty level of skill affect bilateral transfer rate?

- Do the changes in time interval between exercise finish and posttest affect the result of delayed transfer?

\section{MATERIALS AND METHODS}

This study was a semi-empirical and applied research and a pretest-posttest plan with two experimental groups was used.

Subjects. 28 volunteer girl students, with a mean age of $16 \pm 0.93$ years old, were studied. A written consent was obtained from all subjects. Additionally, their personal characteristics and health form was used in order to study their disease history and whether they have a natural eye vision or not. The subjects were randomly divided into two groups $(\mathrm{n}=14)$; Right Exercise as group 1, who performed pretest stage and immediate and delayed transfer tests by the non-superior hand and the exercise stage by the superior one; and Left Exercise as group 2, who performed pretest stage and immediate and delayed transfer tests by the superior hand and the exercise stage by the non-superior one. In order to counterbalance the results, both groups were divided into two subgroups $(n=7)$, differentiated only by performing easy and complex tracking task. None of the subjects had any previous experience in performing tracking task.

Instruments. Personal characteristics questionnaire included individual items related to this study such as age, having no experience of sport activities, having no experience of performing tracking task, and having a natural eye vision. Handedness Inventory of Briggs-Nebes (1975) was used to ensure that all subjects were right-handed (21). Handedness Inventory Briggs-Nebes enjoys a five-step scoring system in which negative and positive points are for the lefthanded and the right-handed, respectively and -24 and 24 represent maximum handedness. According to the guidelines, those who had received a score of 9 or more were allowed to enter the experiment. The software designed for tracking tasks in the present study transferred task acquisition criteria and characteristics of each subject to Excel simultaneously with the implementation of the test. Time to move from the first to the last click for each subject in both easy and difficult tracking tasks was recorded by a computer. Since this instrument measured task acquisition criteria by a computer timer, it owned the required face validity. A preliminary pilot examination was conducted in order to determine the reliability of this tool and resolve its potential problems. Using the test-retest method, reliability of this tool was calculated equal to 0.84 .

Procedure. Easiness or difficulty of tasks was determined based on the goal size and difficulty of goal path. In easy tracking task, the subjects were expected to quickly and accurately follow a circular target with a large size in a hexagonal-designed path which was easy in terms of complexities and curves in 30 seconds, as the highest possible time of marker is on the target. In difficult tracking task, the star-like path had more complexities and curves. The time during which the subjects remained on the path was recorded in each step and the subjects could not see their performance result. In order to avoid falls due to lack of warm-up, the subjects run an attempt freely, the result of which was not considered in next calculations. Research method and project overview are described in Table 1. In all stages, the break time between the attempts and between the tasks were 5 seconds and 10 seconds, respectively. Immediate transfer stage lacked warm-up trial and acquisition 
stage consisted of 3 sessions with 2 blocks

of 12 easy and difficult attempts.

Table 1: Stages and method of conducting the survey for easy and difficult tracking task

\begin{tabular}{|c|c|c|c|c|}
\hline $\begin{array}{l}\text { One-day delayed transfer } \\
\text { Two-day delayed transfer } \\
\text { Seven-day delayed } \\
\text { transfer }\end{array}$ & $\begin{array}{l}\text { Immediate transfer } \\
\text { (10 minutes) }\end{array}$ & $\begin{array}{l}\text { Acquisition (3 } \\
\text { sessions with } 24 \\
\text { attempts) }\end{array}$ & Pre-test & Groups \\
\hline $\begin{array}{l}2 \text { attempts to measure the } \\
\text { non-superior hand }\end{array}$ & $\begin{array}{l}1 \text { attempts to } \\
\text { measure the non- } \\
\text { superior hand }\end{array}$ & $\begin{array}{l}78 \text { exercise } \\
\text { attempts with } \\
\text { superior hand }\end{array}$ & $\begin{array}{l}2 \text { attempts to } \\
\text { measure the non- } \\
\text { superior hand }\end{array}$ & $\begin{array}{c}\text { Group } \\
1\end{array}$ \\
\hline $\begin{array}{l}2 \text { attempts to measure the } \\
\text { superior hand }\end{array}$ & $\begin{array}{l}1 \text { attempts to } \\
\text { measure the superior } \\
\text { hand }\end{array}$ & $\begin{array}{l}78 \text { exercise } \\
\text { attempts with non- } \\
\text { superior hand }\end{array}$ & $\begin{array}{l}2 \text { attempts to } \\
\text { measure the superior } \\
\text { hand }\end{array}$ & $\begin{array}{l}\text { Group } \\
2\end{array}$ \\
\hline
\end{tabular}

Statistical Analysis. Descriptive statistics (mean and standard deviation) and inferential statistics (analysis of variance with repeated measures and $t$-dependent) were used for statistical analysis of data. At the level where mutual effect was significant, dependent-t analysis with correction of degrees of freedom as proposed by Bonferroni was used to identify the pairs which had a significant difference. So, the significance level $(\alpha=0.05)$ was divided by number of tests (stages) to determine the new significance level $(\alpha=0.01)$ to accept the significance of differences. Mauchly's sphericity test was used to check the homogeneity of covariance. Every statistical test was run by SPSS and with a significance level of $\mathrm{p} \leq 0.05$.

\section{RESULTS}

Mauchly's sphericity assumption was rejected $\left(\mathrm{X}^{2}=82.55, \mathrm{p}=0.001\right)$. There is a significant difference $[\mathrm{F}=7.85, \mathrm{p}=0.015]$ between using the superior and non-superior hand. Mean of bilateral transfer of two groups based on handedness (Group $1=$ 8.85 , Group $2=11.36$ ) shows that bilateral transfer from non-superior hand to superior one was more frequent (Table 2).

Also, skill complexity has a significant impact $[\mathrm{F}=31.27, \mathrm{p}=0.001)$ on bilateral transfer. Looking at mean of bilateral transfer of easy tracking task, it can be observed that the subjects had the highest (M $=15.65)$ and the lowest $(\mathrm{M}=11.81)$ performance in two-day delayed transfer of easy tracking task (the second day of test) and in pretest of easy task, respectively. However, in seven-day delayed transfer, mean performance of subjects was almost as much as that of two-day delayed transfer (M $=15.55)$. It was also observed that the subjected recorded the highest $(\mathrm{M}=6.15)$ and the lowest $(\mathrm{M}=3.88)$ performance in seven-day delayed transfer of difficult task and pretest of difficult task, respectively (Table 2).

Table 2: Results of analysis of variance with repeated measures

\begin{tabular}{cccccc}
\hline condition & $\begin{array}{c}\text { Inside-subject } \\
\text { effect }\end{array}$ & Value & $\mathrm{F}$ & $\mathrm{P}$ & $\eta^{2}$ \\
\hline $\begin{array}{c}\text { superior and } \\
\text { non-superior } \\
\text { hand }\end{array}$ & $\begin{array}{c}\text { Wilks' } \\
\text { Lambda }\end{array}$ & 0.62 & 7.857 & 0.015 & 0.37 \\
\hline $\begin{array}{c}\text { skill } \\
\text { complexity }\end{array}$ & $\begin{array}{c}\text { Wilks' } \\
\text { Lambda }\end{array}$ & 0.01 & 31.27 & 0.001 & 0.98 \\
\hline
\end{tabular}


Following the results of Mauchly's test $\left(X^{2}=82.03, p=0.001\right)$, the results of variance analysis showed that the use of superior and superior hand with different time delays has a significant impact on bilateral transfer $\left[\mathrm{F}=27.04, \mathrm{p}=0.001, \eta^{2}=\right.$ $0.65)$.

There is a significant difference between the results of pretest with one-day delayed transfer $(\mathrm{p}=0.001)$, pretest with two-day delayed transfer $(\mathrm{p}=0.001)$, pretest with seven-day delayed transfer $(p=0.001)$, immediate transfer with one-day delayed transfer $(p=0.001)$, and immediate transfer with seven-day delayed transfer $(p=0.001)$. On the other hand, no significant difference was observed between the results of pretest with immediate transfer $(\mathrm{p}=0.016)$, immediate transfer with two-day delayed transfer $(\mathrm{p}=0.692)$, one-day delayed transfer with two-day delayed transfer $(\mathrm{p}=$ 0.089), and two-day delayed transfer with seven-day delayed transfer $(\mathrm{p}=0.043)$ (Table 3).

Table 3: Dependent-t test to compare the results of different stages of easy tracking task with superior hand

\begin{tabular}{lccc}
\multicolumn{1}{c}{ Stages } & Mean difference & $\mathrm{t}$ & $\mathrm{p}$ \\
\hline Pretest - immediate transfer & -3.719 & -2.776 & 0.016 \\
\hline Pretest - one-day delayed transfer & -4.029 & -3.125 & $0.001^{*}$ \\
\hline Pretest - two-day delayed transfer & -4.159 & -2.594 & $0.001^{*}$ \\
\hline Pretest - seven-day delayed transfer & -3.517 & -2.655 & $0.001^{*}$ \\
\hline Immediate transfer - one-day delayed transfer & -0.31 & -3.479 & $0.001^{*}$ \\
\hline Immediate transfer - two-day delayed transfer & -0.44 & -0.405 & 0.692 \\
\hline Immediate transfer - seven-day delayed transfer & 0.201 & -0.219 & $0.001^{*}$ \\
\hline One-day delayed transfer - two-day delayed transfer & -0.13 & -0.14 & 0.089 \\
\hline One-day delayed transfer - seven-day delayed transfer & 0.511 & -0.641 & 0.071 \\
\hline Two-day delayed transfer - seven-day delayed transfer & 0.641 & -0.883 & 0.043 \\
\hline
\end{tabular}

There is a significant difference between the results of pretest with immediate transfer $(\mathrm{p}=0.001)$, pretest with one-day delayed transfer $(\mathrm{p}=0.001)$, pretest with seven-day delayed transfer $(\mathrm{p}=0.001)$, immediate transfer with one-day delayed transfer $(\mathrm{p}=$ 0.001), immediate transfer with seven-day delayed transfer $(\mathrm{p}=0.001)$, one-day delayed transfer with two-day delayed transfer $(\mathrm{p}=0.001)$, and two-day delayed transfer with seven-day delayed transfer $(\mathrm{p}=$ $0.001)$. In contrast, no significant difference was observed between pretest with two-day delayed transfer $(p=0.033)$ and immediate transfer with two-day delayed transfer $(\mathrm{p}=0.046)$ (Table 4).

Table 4: Dependent-t test to compare the results of different stages of easy tracking task with non-superior hand

\begin{tabular}{lllc}
\multicolumn{1}{c}{ Stages } & Mean difference & $\mathrm{t}$ & $\mathrm{p}$ \\
\hline Pretest - immediate transfer & -7.285 & -10.60 & $0.001^{*}$ \\
\hline Pretest - one-day delayed transfer & -5.683 & -9.545 & $0.001^{*}$ \\
\hline Pretest - two-day delayed transfer & -5.332 & -9.043 & 0.033 \\
\hline Pretest - seven-day delayed transfer & -3.96 & -6.431 & $0.001^{*}$ \\
\hline Immediate transfer - one-day delayed transfer & 6.601 & 7.51 & $0.001^{*}$ \\
\hline Immediate transfer - two-day delayed transfer & -2.047 & -8.043 & 0.046 \\
\hline Immediate transfer - seven-day delayed transfer & -5.675 & -8.744 & $0.001^{*}$ \\
\hline One-day delayed transfer - two-day delayed transfer & -4.648 & -6.524 & $0.001^{*}$ \\
\hline One-day delayed transfer - seven-day delayed transfer & -6.277 & -7.144 & $0.001^{*}$ \\
\hline Two-day delayed transfer - seven-day delayed transfer & -4.628 & -3.566 & $0.001^{*}$ \\
\hline
\end{tabular}


There is a significant difference between pretest with immediate transfer $(\mathrm{p}=0.001)$, pretest with one-day delayed transfer $(\mathrm{p}=$ $0.001)$, pretest with two-day delayed transfer $(p=0.001)$, pretest with seven-day delayed transfer $(\mathrm{p}=0.001)$, immediate transfer with seven-day delayed transfer $(\mathrm{p}=0.001)$, oneday delayed transfer with seven-day delayed transfer $(\mathrm{p}=0.001)$, and two-day delayed transfer with seven-day delayed transfer $(\mathrm{p}=$ $0.001)$. On the other hand, the difference between immediate transfer with one-day delayed transfer $(\mathrm{p}=0.618)$, immediate transfer with two-day delayed transfer $(\mathrm{p}=$ 0.412 ), and one-day delayed transfer with two-day delayed transfer $(\mathrm{p}=0.072)$ (Table $5)$.

Table 5: Dependent-t test to compare the results of different stages of difficult tracking task with superior hand

\begin{tabular}{lccc}
\multicolumn{1}{c}{ Stages } & Mean difference & $\mathrm{t}$ & $\mathrm{p}$ \\
\hline Pretest - immediate transfer & -7.578 & -6.034 & $0.001^{*}$ \\
\hline Pretest - one-day delayed transfer & -6.81 & -3.728 & $0.001^{*}$ \\
\hline Pretest - two-day delayed transfer & -9.072 & -7.408 & $0.001^{*}$ \\
\hline Pretest - seven-day delayed transfer & -5.02 & -4.852 & $0.001^{*}$ \\
\hline Immediate transfer - one-day delayed transfer & -1.231 & -0.51 & 0.618 \\
\hline Immediate transfer - two-day delayed transfer & -1.493 & -0.848 & 0.412 \\
\hline Immediate transfer - seven-day delayed transfer & -7.441 & -5.862 & $0.001^{*}$ \\
\hline One-day delayed transfer - two-day delayed transfer & -2.262 & -0.465 & 0.072 \\
\hline One-day delayed transfer - seven-day delayed transfer & -8.21 & -6.511 & $0.001^{*}$ \\
\hline Two-day delayed transfer - seven-day delayed transfer & -6.052 & -2.099 & $0.001^{*}$ \\
\hline
\end{tabular}

There is a significant difference between pretest with one-day delayed transfer $(p=0.001)$, pretest with two-day delayed transfer $(\mathrm{p}=0.001)$, pretest with seven-day delayed transfer $(\mathrm{p}=0.001)$, immediate transfer with seven-day delayed transfer $(\mathrm{p}=0.001)$, one-day delayed transfer with two-day delayed transfer $(\mathrm{p}=0.001)$, and two-day delayed transfer with seven-day delayed transfer $(\mathrm{p}=0.001)$. By contrast, there is no significant difference between pretest with immediate transfer $(\mathrm{p}=0.01)$, immediate transfer with one-day delayed transfer $(\mathrm{p}=0.321)$, and immediate transfer with two-day delayed transfer $(\mathrm{p}=0.477)$ (Table 6).

Table 6: Dependent-t test to compare the results of different stages of difficult tracking task with non-superior hand

\begin{tabular}{lccc}
\hline \multicolumn{1}{c}{ Stages } & Mean difference & $\mathrm{t}$ & $\mathrm{p}$ \\
\hline Pretest - immediate transfer & -2.241 & -3.037 & $0.01^{*}$ \\
\hline Pretest - one-day delayed transfer & -1.412 & -4.711 & $0.001^{*}$ \\
\hline Pretest - two-day delayed transfer & -3.19 & -3.678 & $0.001^{*}$ \\
\hline Pretest - seven-day delayed transfer & -3.532 & -2.359 & $0.001^{*}$ \\
\hline Immediate transfer - one-day delayed transfer & 0.829 & 1.031 & 0.321 \\
\hline Immediate transfer - two-day delayed transfer & -0.948 & -0.732 & 0.477 \\
\hline Immediate transfer - seven-day delayed transfer & -1.29 & -0.827 & $0.001^{*}$ \\
\hline One-day delayed transfer - two-day delayed transfer & -6.847 & 4.585 & $0.001^{*}$ \\
\hline One-day delayed transfer - seven-day delayed transfer & -2.12 & -1.497 & $0.001^{*}$ \\
\hline Two-day delayed transfer - seven-day delayed transfer & -0.342 & -0.262 & $0.001^{*}$ \\
\hline
\end{tabular}

\section{DISCUSSION}

The present paper aimed to study the effect of skill complexity during three time delays on bilateral transfer of easy and difficult tracking task. The results suggest the existence of bilateral transfer in both 
groups of subjects, but the mean bilateral transfer in Group 2 (Left exercise) was higher than that of Group 1 (Right exercise). In other words, the bilateral transfer from non-superior hand to superior hand was more frequent than the bilateral transfer in the opposite direction. These results are consistent with the findings of Liu and Wrisberg (2005), Kumar and Mandal (2005), Ghaleh et al. (2009), Weigelt (2002), Inui (2005), Stoeckel, Hartmann, and Weigelt (2007), Cote, Kimmerle, and Paterson (2007), Pan and van Gemmert (2013), Bagherzadeh et al. (2004), and Rafiee, Vaezmousavi, and Abdoli (2010) (5-7, 1318, 20), but inconsistent with the results obtained by Darden (1995), Teixeira (2000), Baliarsing, Doi, and Hattori (2002), Noguchi (2009), and Keshavarzi and Farokhi (2006) (8-12). It seems that exchange of information between the hemispheres of the brain and also different roles of brain hemispheres in controlling different movements is one of the reasons for superiority of hands over each other. Explaining the contradictions in bilateral transfer, it can be mentioned that these results may be due to the problem in measuring the transfer. So, it is of great importance to know which transfer formula is used for a given test, especially when one asks for the domain and direction of transfer. Furthermore, different factors may affect the results of the transfer, like the circumstances in which the subjects are tested (7).

In order to study the effect of time on bilateral transfer, three one-day, two-day, and seven-day delays were established. Results showed that the lowest performance in both easy and difficult tasks belonged to pretest stage. Then during the acquisition phase, it was observed that the desired task was learned, resulting in a significant increase in mean performance of subjects in immediate transfer stage. In two-day delayed transfer stage, the highest performance of the subjects in easy tracking task was observed.
Additionally, an increase was observed in average performance of the subjects in difficult task, reaching a peak in seven-day delayed transfer stage. In fact, in difficult tracking task, a gradual increase in the amount of bilateral transfer over time delays was observed. These results are consistent with the findings of Liu and Wrisberg (2005), and Ghaleh et al. (2009) (5, 7), it should be noted that the maximum time delay was 24 hours in these three mentioned studies. Possible justification for effectiveness of time on bilateral transfer and the results of the present study can be considered from multiple perspectives. In terms of learning and motion control, theories of memory consolidation and processing levels can be taken into account. These theories indicate that durability of memory impact is a function of reinforced experiences in specific tasks and the more the durability of memory impact for initial tasks, the more the positive transfer (7). In other words, perhaps each of these phases played a role in an exercise session for delayed transfer stage and finally yielded such results. Since tracking task is continuous task, its learning, retention, and transfer can be reviewed through Adams' closed loop theory (1970) which is mainly about linear and slow motions. According to this theory, motions are done by comparing the feedbacks from motion during its implementation and cognitive rejection. In other words, one uses cognitive rejection at the beginning of learning to achieve a more accurate motion (22). On the other hand, there is a dramatic difference between retention characteristics of continuous and single tasks. Continuous tasks are mostly maintained over long retention intervals, while retention is weak in single tasks. This implies that when bilateral transfer is supposed to be used in order to save time and money or for rehabilitation of athletes and non-athletes, the task can be concentrated on the non-superior organ, so 
that more bilateral transfer can be expected. Like other retention tests, continuous task over time would bear durable effects and not be afflicted by forgetfulness.

\section{CONCLUSION}

About the effect of task type on bilateral transfer, the results showed that bilateral transfer was more frequent in easy task compared with difficult task in all stages. The difference between easy and difficult tasks in terms of the amount of bilateral transfer is probably related to skill complexity. In fact, in easy tracking task, due to the ease of information processing, a subject faster goes through cognitive and perceptual-motion stages. On the other hand, difficult tracking task needs more time for learning, retention, and transfer, because it imposes an additional cognitive load on the data processing system. As a result, more bilateral transfer occurs in easy task than difficult task. This indicates that when bilateral transfer is supposed to be used in order to save time and money or for rehabilitation of athletes and non-athletes, complexity of sport skill or rehabilitating task should be specially taken into account. In sport skills or rehabilitating tasks for which a higher level of complexity is defined, regarding the topic of motor control, less bilateral transfer is expected than easier tasks and activities. This should be considered in planning exercise sessions and rehabilitating tasks with different levels of complexity. In addition, according to the result that the maximum bilateral transfer in easy and difficult tracking task occurs respectively on the second and the seventh days, it can be stated that bilateral transfer takes place apart from the skill complexity but complexity of the studied task can affect the time of reaching the maximum bilateral transfer. The rate of bilateral transfer in the first sessions of posttest is higher in the tasks that are easier and do not have a high complexity compared with more complex skills, in which the maximum bilateral transfer is expected to appear in the next sessions of posttest. Possible reasons for this difference should be sought in the characteristics of skill and various conditions of acquisition, retention, and transfer of easy and difficult tasks.

The followings are possible problems affecting the results of the present study and insignificance of some stages:

1- Newness and innovativeness of implemented task and tracking task in this study.

2- Intervals to define the delays that may not be well defined and variations in these intervals may change the result of delayed transfer.

3- Definition of easy and difficult tracking task based on complexity of path and size of target circle which may have not been a proper definition of and criterion for easy and difficult tracking task.

4- Insensitivity of measurement software and unfamiliarity of the subjects with the task, working with mouse, and computer all have affected the results.

It is recommended that a similar study to be done with a change in the criterion of skill complexity and interval from the end of exercise to posttest in order to study the effect of the delays more than one week. To avoid the effect of repeated performances on the results of the subjects in separate groups, further tests are better to be done. Since the task performed in the present study was a laboratory and continuous skill, accuracy of results is recommended to be examined on field cases and single sport skills. Given the focus of the present study on right-handed subjects and the results, another study is needed to be conducted on left-handed subjects whose left hand seems to be involved in implementation of an action, on top of its planning. Finally, it is recommended that all above-mentioned items to be separately tested on girls and boys in different ages. 


\section{REFFRENCES}

1. Dunham P. Effect of Practice Order on the Efficiency of Bilateral Skill Acquisition. Research Quarterly American Alliance for Health, Physical Education and Recreation. 1977;48(2):284-7.

2. Magill RA. Motor Learning: Concepts and Applications. 6th ed: McGraw-Hill; 2001.

3. Bhushan B, Dwivedi CB, Mishra R, Mandal MK. Performance on a mirror-drawing task by non-right-handers. The Journal of general psychology. 2000;127(3):271-7. Epub 2000/09/07.

4. Woodworth RS, Schlosberg H. Experimental psychology: Holt; 1954. 948 p.

5. Liu J, Wrisberg CA. Immediate and delayed bilateral transfer of throwing accuracy in male and female children. Research quarterly for exercise and sport. 2005;76(1):20-7. Epub 2005/04/07.

6. Kumar S, Mandal MK. Bilateral transfer of skill in left- and right-handers. Laterality. 2005;10(4):337-44. Epub 2005/07/16.

7. Ghaleh S, Vaezmousavi MK, Namazizadeh M, Allahyari A. Comparing Immediate and Delayed Bilateral Transfer in Children's and Adult's Throwing Skill Journal of Motor Behavior and Sport Psychology. 2009(1):319-26 [Article in Farsi].

8. Baliarsing AS, Doi K, Hattori Y. Bilateral elbow flexion reconstruction with functioning free muscle transfer for obstetric brachial plexus palsy. Journal of hand surgery (Edinburgh, Scotland). 2002;27(5):484-6. Epub 2002/10/09.

9. Darden GF. The Effect of Practice Sequence on the Transfer of Learning for a Novel Bilateral Lacrosse Skill. Research quarterly for exercise and sport. 1997;68(1):A-58-9.

10. Keshavarzi HR, Farokhi A. The Effects of Strengthening Exercise on Dominant and Non - Dominant Leg. HARAKAT. 2006(27):129-36 [Article in Farsi].

11. Noguchi T, Demura S, Nagasawa Y, Uchiyama M. Influence of measurement order by dominant and nondominant hands on performance of a pursuit-rotor task. Perceptual and motor skills. 2009;108(3):905-14. Epub 2009/09/04.

12. Teixeira LA. Timing and force components in bilateral transfer of learning. Brain and cognition. 2000;44(3):45569. Epub 2000/12/06.

13. Bagherzadeh FA, Sheikh M, Tahmasebi S, Shahbazi M. The Study of Bilateral Transfer of Badminton Short Service Skill of Preferred Hand to Non-Preferred Hand and Vice Versa. Harakat. 2004(21):45-50 [Article in Farsi].

14. Cote P, Kimmerle M, Paterson J. Bilateral Transfer of Motor Skills in Dance. Research quarterly for exercise and sport. 2007;78(1):A-15-A-6 [Reseach Consortium Abstracts].

15. Inui N. Lateralization of bilateral transfer of visuomotor information in right-handers and left-handers. Journal of motor behavior. 2005;37(4):275-83. Epub 2005/06/22.

16. Pan Z, van Gemmert AWA. The direction of bilateral transfer depends on the performance parameter. Human Movement Science. 2013;32(5):1070-81.

17. Rafiee S, Vaezmousavi MK, Abdoli B. Direction and rate of errors in bilateral transfer of dart throwing. Journal of Motor Behavior and Sport Psychology. 2010(2):315-22 [Article in Farsi].

18. Stoeckel T, Hartmann C, Weigelt M. Effects of bilateral practice on the acquisiton of complex sport skills: A basketball study with school children. German Journal of Sport Psychology (ZEITSCHRIFT FUR SPORTPSYCHOLOGIE). 2007;14(3):130-5.

19. Uehara I. No transfer of visuomotor learning of button-pressing from right to left hands in right-handed fouryear-olds. Perceptual and motor skills. 1998;87(3 Pt 2):1427-40. Epub 1999/03/03.

20. Weigelt M. Practice Variability Effects on Bilateral Transfer for a Novel Ball Bouncing Task. Research quarterly for exercise and sport. 2002;73(Supplement 1):44-5 [Abstracts of Completed Research].

21. Briggs GG, Nebes RD. Patterns of hand preference in a student population. Cortex; a journal devoted to the study of the nervous system and behavior. 1975;11(3):230-8. Epub 1975/09/01.

22. Schmidt RA, Lee TD. Motor Control and Learning: A Behavioural Emphasis. 5th ed: Human Kinetics; 2011. 581 p. 


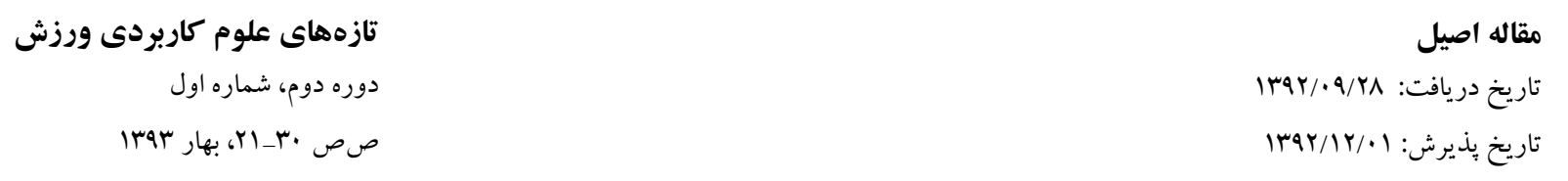

\section{اثر يِيجيدَى مهارت طى تأخيرهاى زمانى متفاوت بر انتقال دوسويه}

\section{'زهرا ذوالفقارى*، 'احسان زارعيان، 'زهرا سلمان}

ا. كارشناس ارشد رفتار حركتى، دانشكده تربيتبدنى و علوم ورزشى، دانشخاه علامه طباطبايى، تهران، ايران.

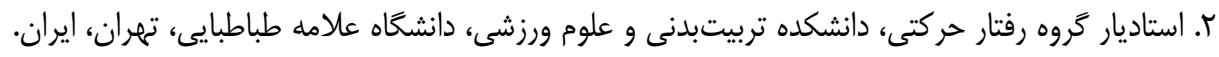

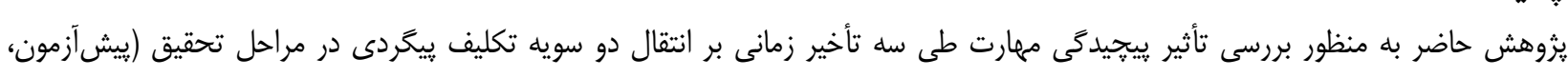

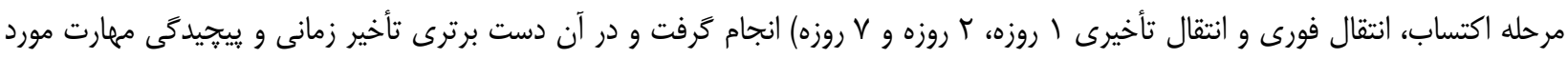

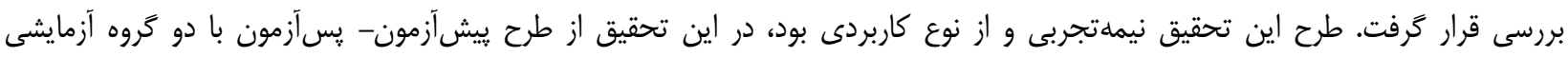

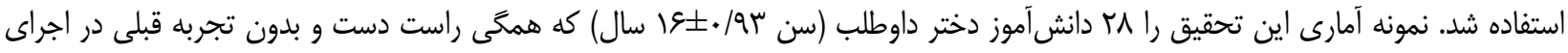

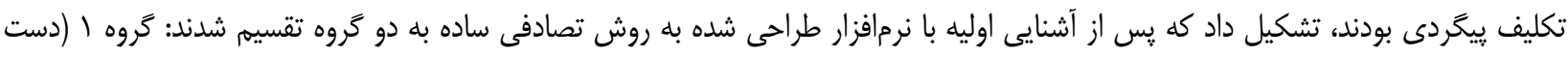

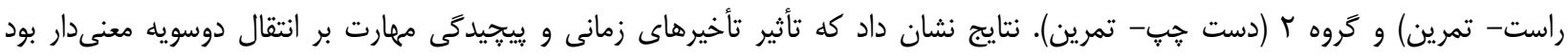

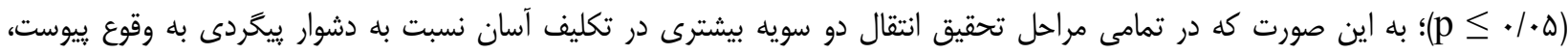

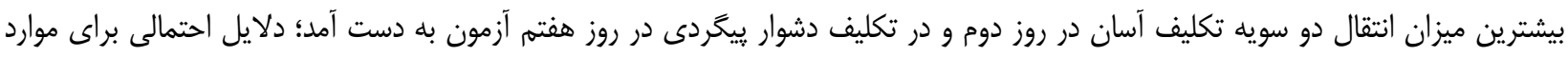

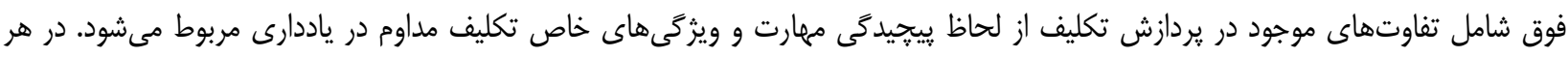

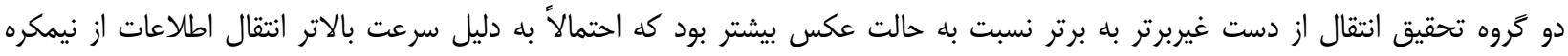

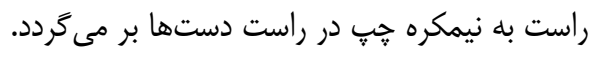

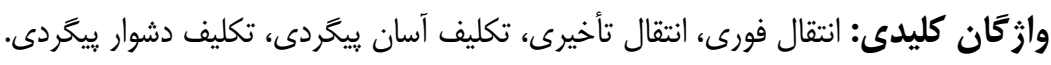

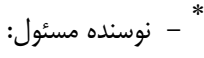

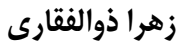

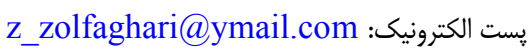

